\title{
Article
}

\section{The Blockade of Tumoral IL1 $\beta$-Mediated Signaling in Normal Colonic Fibroblasts Sensitizes Tumor Cells to Chemotherapy and Prevents Inflammatory CAF Activation}

\author{
Natalia Guillén Díaz-Maroto ${ }^{1,2}$, Gemma Garcia-Vicién ${ }^{1,2} \oplus$, Giovanna Polcaro ${ }^{3}$, María Bañuls ${ }^{1}$, Nerea Albert ${ }^{1,2}$, \\ Alberto Villanueva ${ }^{1,2}$ and David G. Molleví ${ }^{1,2, * \mathbb{D}}$ \\ 1 Program Against Cancer Therapeutic Resistance (ProCURE), Catalan Institute of Oncology, \\ 08908 L'Hospitalet de Llobregat, Spain; nguillen@iconcologia.net (N.G.D.-M.); ggarciav@idibell.cat (G.G.-V.); \\ mbanuls@iconcologia.net (M.B.); nalbert@idibell.cat (N.A.); avillanueva@iconcologia.net (A.V.) \\ 2 Tumoral and Stromal Chemoresistance Group, Molecular Mechanisms and Experimental Therapy in \\ Oncology Program (ONCOBELL), Institut d'Investigació Biomèdica de Bellvitge_-IDIBELL, \\ 08908 L'Hospitalet de Llobregat, Spain \\ 3 Dipartimento Scienze e Tecnologie, Universita degli Studi del Sannio, 82100 Benevento, Italy; \\ giovanna.polcaro@hotmail.it \\ * Correspondence: dgmollevi@iconcologia.net; Tel.: +34-932607370
}

Citation: Díaz-Maroto, N.G.; Garcia-Vicién, G.; Polcaro, G.; Bañuls, M.; Albert, N.; Villanueva, A.; Molleví, D.G. The Blockade of Tumoral IL1 $\beta$-Mediated Signaling in Normal Colonic Fibroblasts Sensitizes Tumor Cells to Chemotherapy and Prevents Inflammatory CAF Activation. Int. J. Mol. Sci. 2021, 22 4960. https://doi.org/10.3390/ ijms22094960

Academic Editor: Carmine Stolfi

Received: 6 April 2021

Accepted: 5 May 2021

Published: 7 May 2021

Publisher's Note: MDPI stays neutral with regard to jurisdictional claims in published maps and institutional affiliations.

Copyright: (C) 2021 by the authors Licensee MDPI, Basel, Switzerland. This article is an open access article distributed under the terms and conditions of the Creative Commons Attribution (CC BY) license (https:// creativecommons.org/licenses/by/ $4.0 /)$

\begin{abstract}
Heterotypic interactions between newly transformed cells and normal surrounding cells define tumor's fate in incipient carcinomas. Once homeostasis has been lost, normal resident fibroblasts become carcinoma-associated fibroblasts, conferring protumorogenic properties on these normal cells. Here we describe the IL1 $\beta$-mediated interplay between cancer cells and normal colonic myofibroblasts (NCFs), which bestows differential sensitivity to cytotoxic drugs on tumor cells. We used NCFs, their conditioned media (CM), and cocultures with tumor cells to characterize the IL1 $\beta$-mediated crosstalk between both cell types. We silenced IL1 $\beta$ in tumor cells to demonstrate that such cells do not exert an influence on NCFs inflammatory phenotype. Our results shows that IL1 $\beta$ is overexpressed in cocultured tumor cells. IL1 $\beta$ enables paracrine signaling in myofibroblasts, converting them into inflammatory-CAFs (iCAF). IL1 $\beta$-stimulated-NCF-CM induces migration and differential sensitivity to oxaliplatin in colorectal tumor cells. Such chemoprotective effect has not been evidenced for TGF $\beta 1$-driven NCFs. IL1 $\beta$ induces the loss of a myofibroblastic phenotype in NCFs and acquisition of iCAF traits. In conclusion, IL1 $\beta$-secreted by cancer cells modify surrounding normal fibroblasts to confer protumorogenic features on them, particularly tolerance to cytotoxic drugs. The use of IL1 $\beta$-blocking agents might help to avoid the iCAF traits acquisition and consequently to counteract the protumorogenic actions these cells.
\end{abstract}

Keywords: interleukin 1 beta; tumor microenvironment; stroma; resistance; myofibroblasts; inflammatory CAFs

\section{Introduction}

During the initial steps of the tumorigenic process, newly transformed malignant cells compete with the normal microenvironment to overcome the inhibitory signals that normal tissue imposes [1]. However, once the homeostatic balance has been lost (e.g., due to cytokine disbalance) cells of the normal tissue surrounding tumors (e.g., fibroblasts, macrophages, etc.) become potent protumorigenic inducers, providing support for tumor proliferation, survival, immune evasion and invasiveness [2,3]. In a similar vein to the angiogenic switch [4], resident fibroblasts undergo a switch to become carcinoma-associated fibroblasts (CAFs). Of the various hypotheses that have been proposed [5], the most plausible is that pericryptal fibroblasts subjacent to the basement membrane enveloping epithelial glands become activated when tumor cells disrupt the basal membrane and start to invade. Such activation depends on juxtacrine and paracrine bidirectional crosstalk [6], 
which is mainly mediated by integrins, cadherins, soluble factors [7], and exosome cargo [8]. After epithelial malignization, pericryptal fibroblasts activate several mechanisms of innate inflammatory signals, MAP3K8 and IL1R1 being key mediators in the process [9].

A large number of soluble factors are known to be involved in this crosstalk. However, it is difficult to identify a trigger; it probably depends on multiple factors and is likely to be organ-dependent. Interleukin $1 \alpha$ has been proposed as leading the tumor-stroma crosstalk to sustain the expression of inflammatory mediators by CAFs in pancreatic [10] and prostate tumors [11]. Moreover, tumor-derived interleukin $1 \beta$ (IL1 $\beta$ ) has been associated with the conversion of fibroblasts into CAFs in squamous cell carcinoma [12]. In addition, blocking the interaction of IL1 $\beta$ with its receptor IL1R1, which is overexpressed in normal fibroblasts relative to CAFs $[13,14]$, reprograms CAFs to hinder oral carcinogenesis [15]. Interestingly, IL1 $\beta$-deficient mice do not develop tumors, unlike wild-type animals [16]. Other authors have reported that tumor cell-derived IL1 $\alpha$ induces HGF secretion by CAFs, enhancing in turn the metastatic potential of tumor cells [17].

However, the involvement of interleukin 1 family cytokines in chemoresistance has not been fully elucidated. Mendoza-Rodriguez et al. reported that IL1 $\beta$ induces the overexpression of an IAP family protein (BIRC3), conferring doxorubicin resistance on breast cancer cells [18]. In addition, it has recently been reported that the blockade of stromal IL1 $\beta$ renders PDAC tumors less fibrotic and more sensitive to gemcitabine [19].

Several studies have examined the interaction between tumor cells and CAFs in various cancer types, but few have addressed the early steps of the heterotypic interactions between resident normal fibroblasts and tumor cells, and how the inflammatory signals provided by the tumor create a refuge to avoid the damage induced by chemotherapy. Here, we explore how cancer cell-derived IL1 $\beta$ induces paracrine signaling in fibroblasts that causes resistance to oxaliplatin (L-OHP; a DNA inter and intra-strand cross link inducer) in colorectal cancer cell lines.

\section{Results}

\subsection{IL1 3 mRNA Expression in Colorectal Cell Lines, Fibroblasts and Cocultures}

The level of IL1 $\beta$ mRNA expression was measured in 13 CCCL monocultures, and 11 NCFs and 15 CAFs from colorectal cancer patients. As shown in Figure 1A, levels in CCCL were highly variable, but lower than values detected in NCFs and CAFs, with mean relative expression values of 0.016 (95\% CI: 0.007-0.026) in tumor cells vs. 1.05 (95\% CI: $0.25-1.84$ ) in NCFs and 2.86 (95\% CI: 1.2-4.52) in CAFs. These were approximately 60 and > 150 times higher in NCFs and CAFs, respectively. However, after 5 days in transwell coculture with NCFs the mRNA expression values of DLD1 cells increased $>170$-fold on average, while the increase in cocultured NCFs was more modest (2.5-fold on average), although the latter attained values were comparable to those of their paired CAFs (Figure 1B,C).

\subsection{IL1 $\beta$ Receptor Expression in Colorectal Cell Lines and NCFs}

Regarding the expression of the IL1 $\beta$ receptors, IL1R1 and IL1R2, IL1R1 was strongly expressed in fibroblasts while colorectal tumor cell lines expressed extremely low levels of the receptor (Figure 1D,E). Interestingly, the decoy receptor IL1R2 was expressed at low levels in fibroblasts, while its expression in tumor cells was variable but high in most of the CCCL tested (Figure 1F,G).

In addition, the expression of the receptors was regulated by IL1 $\beta$ in NHFs and NCFs, since the expression of both IL1R1 and IL1R2 increased after stimulation with IL1 $\beta$, while receptors in tumor cells (SW480 and DLD1) were not affected by IL1 $\beta$, probably due to the high basal levels of expression of the decoy receptor IL1R2 in those cancer cells (Figure 1H). 
A

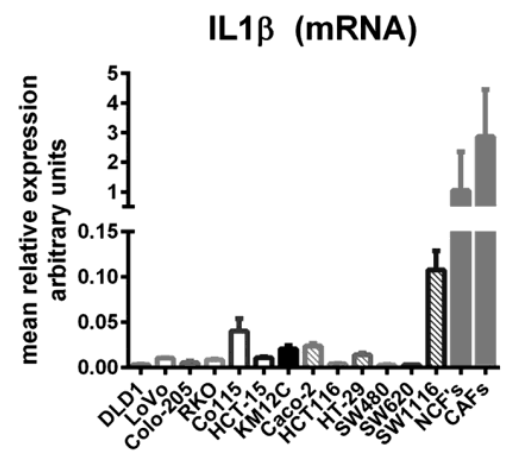

B

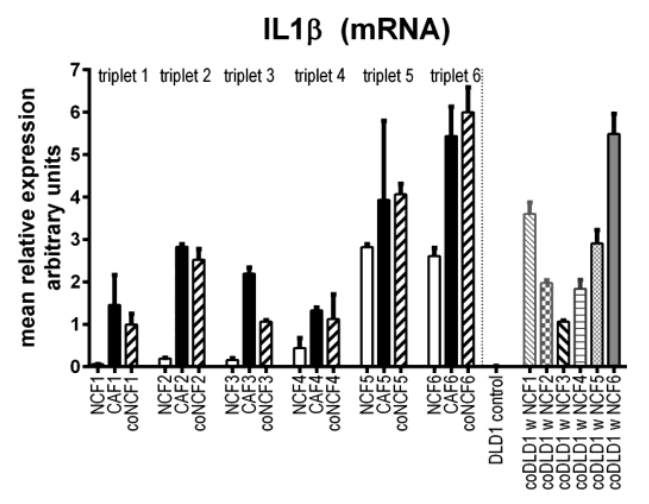

C

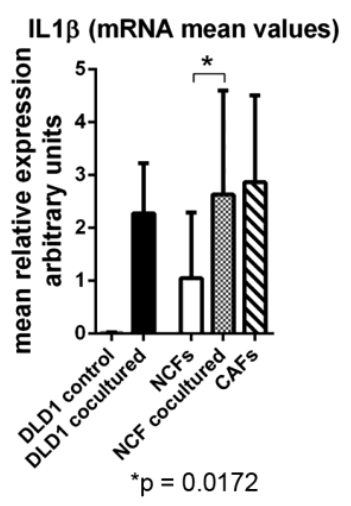

D

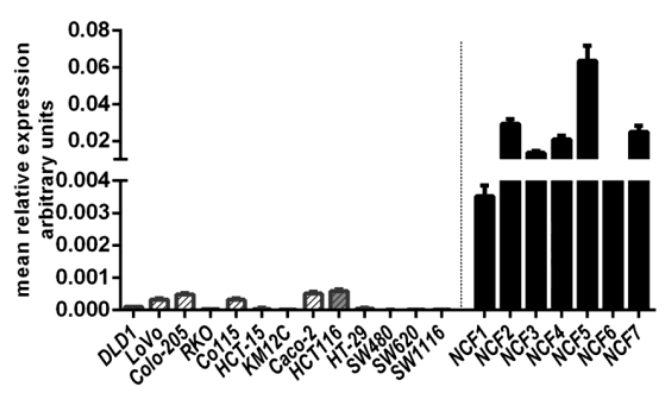

F

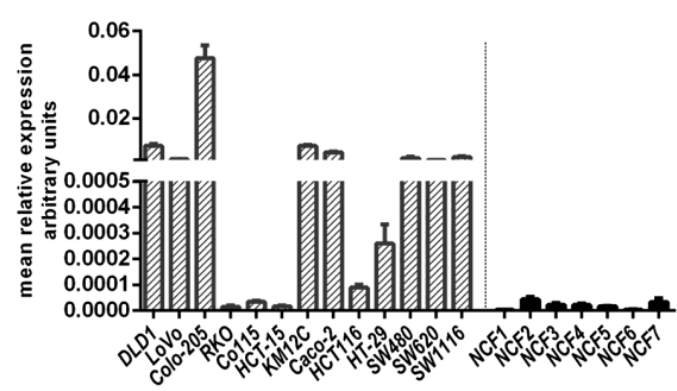

E

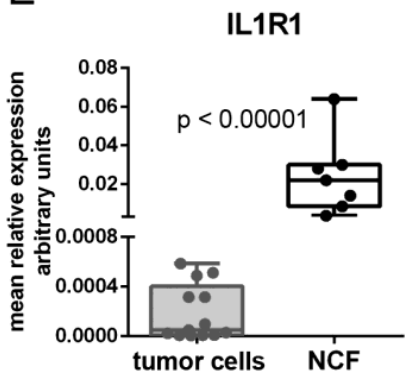

$\mathrm{H}$

\section{IL1 $\beta$ receptors}

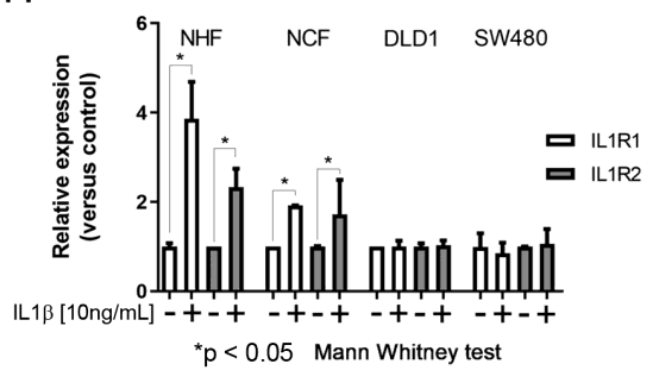

G IL1R2

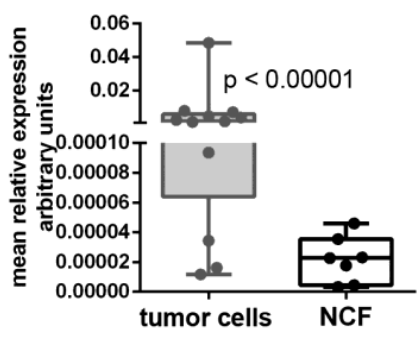

Figure 1. (A) mRNA levels of IL1 $\beta$ in 13 colorectal cell lines (DLD1, LoVo, Colo-205, RKO, Co115, HCT-15, KM12C, Caco-2, HCT116, HT-29, SW480, SW620, and SW1116) and in a mean of 11 normal colonic fibroblasts (NCFs) and a mean of 15 carcinoma-associated fibroblasts (CAFs). Bars depicted mean $+\mathrm{sd}$ of four independent biological replicates of three technical replicates each. Expression is reported as relative values corrected by housekeeping gene expression (GAPDH). (B) mRNA 
levels of IL1 $\beta$ in NCFs (cultured alone; depicted as white bars), paired CAFs (from the same patient; black bars) and the NCFs cultured with DLD1 cells (in transwell inserts; dashed bars). Thus, we had six different triplets, consisting in NCF and CAF from the same patient, and the NCF cocultured with DLD1 cells. In addition, we show IL1 $\beta$ mRNA levels in cocultured DLD1 cells with each of the $6 \mathrm{NCF}$, compared with the DLD1-monocultured controls. Bars depicted mean $+\mathrm{sd}$ of four independent biological replicates. Expression is reported as relative values corrected by housekeeping gene expression (GAPDH). (C) mean values of mRNA IL1 $\beta$. After coculturing, DLD1 cells attain values like those in NCFs and CAFs. Cocultured NCFs also increase mRNA levels to the same values as CAFs (Mann-Whitney U test; Expression is reported as relative values corrected by housekeeping gene expression (GAPDH). (D) mRNA relative levels of IL1R1 receptor (in relation to housekeeping gene GAPDH) in 13 colorectal cell lines and in 7 NCFs. (E) Mean values of IL1R1 between colorectal cell lines and NCFs are significantly different $(p<0.00001$; Mann-Whitney U test). (F) mRNA levels of IL1R2 decoy receptor in 13 colorectal cell lines and in 7 NCFs. (G) Mean values of IL1R2 between colorectal cell lines and NCFs are significantly different $(p<0.00001$; Mann-Whitney U test). (H) mRNA levels of IL1R1 and IL1R2 increase after stimulation with IL1 $\beta$ in normal hepatic fibroblasts (NHFs) and NCFs. Conversely, stimulation in tumor cells produced no increase in either IL1 $\beta$ receptor. Bars depicted mean + sd of three independent replicates. Expression values adjusted by housekeeping gene expression (GAPDH). Data were normalized to each respective control without IL1 $\beta$.

\subsection{Differential Impact of IL1 $\beta$ on the Proliferation of Tumor Cells and Fibroblasts}

The aforementioned results imply that IL1 $\beta$ might act first in a paracrine manner from tumor cells to myofibroblasts, and that an autocrine loop might maintain the activated fibroblast phenotype after fibroblast activation. In fact, we observed that, after IL1 $\beta$ stimulation, NCFs lost their myofibroblastic features ( $\alpha$ SMA, Calponin, and Synaptopodin expression) and overexpressed FAP (Figure 2A). We first checked whether proliferation might be stimulated after culturing cells, CCCL and fibroblasts, with $(10 \mathrm{ng} / \mathrm{mL})$ of IL1 $\beta$. As shown in Figure 2B, 5 out of 7 colorectal cells lines showed no increase in proliferation after exposure to IL1 $\beta$. Conversely, NCFs and NHFs both showed increased proliferation after $(10 \mathrm{ng} / \mathrm{mL})$ IL1 $\beta$ stimulation. This proliferation is controlled by blocking the action of IL1 $\beta$, either by acting on one of the most important effectors of the pathway, P38 by the addition of a P38 inhibitor VX-702 (400 nM), or by altering the binding of the cytokine with its receptor with a neutralizing IL1 $\beta$ antibody (Figure $2 \mathrm{C}$ ).

Using the two cell lines that responded to IL1 $\beta$, we conducted a dose-response assay, in which HCT116 increased proliferation according to the increase in IL1 $\beta$ (Figure 2D; statistically significant only at $10 \mathrm{ng} / \mathrm{mL}$ IL1 $\beta$ ), while HT29 slightly increased proliferation but was not associated with an increase in IL1 $\beta$ (Figure 2E). However, this increase was not associated with an increase in viability after culturing cells with $2 \mu \mathrm{M}$ L-OHP.

\subsection{Exploring the Effect of IL1 $\beta$ and Its Targets on Fibroblast and Tumor Cell Migration and Recruitment}

We explored other protumorogenic properties, such as migration, on which IL1 $\beta$ and their soluble targets could be altering the crosstalk between tumor cells and fibroblasts. Fibroblast migration was stimulated after IL1 $\beta$ administration, both, in a wound-healing assay (Figure 2F; $p=0.0035$ Kruskal-Wallis test, with Dunn's post hoc multiple comparison test) and directional migration using transwell inserts (Figure $2 \mathrm{H}$; adjusted $p=0.0034$ Kruskal-Wallis test, with Dunn's post hoc multiple comparison test), while DLD1 cells did not increase migration as expected. When we used CM from IL1 $\beta$-stimulated NCF ( $48 \mathrm{~h}$ of fibroblast stimulation), IL1 $\beta$ targets secreted into the culture medium from NCFs enhanced the migratory capabilities of tumor cells to an almost statistically significant extent relative to control or NCF CM (Kruskal-Wallis test, with Dunn's post hoc multiple comparison test, adjusted $p=0.051$; Figure 2G). Directional migration of DLD1 cells in coculture with NCFs was also diminished with the use of neutralizing antibody against IL1 $\beta(p=0.0006, \mathrm{U}$ Mann-Whitney test; Figure 2I). Thus, blocking the action of IL1 $\beta$ disrupted the migratory capabilities of tumor cells and restored the myofibroblastic phenotype of NCFs as observed at the protein level for FAP and $\alpha$ SMA (Figure 2J). 
A IL1 $\beta$-stimulated NCF B

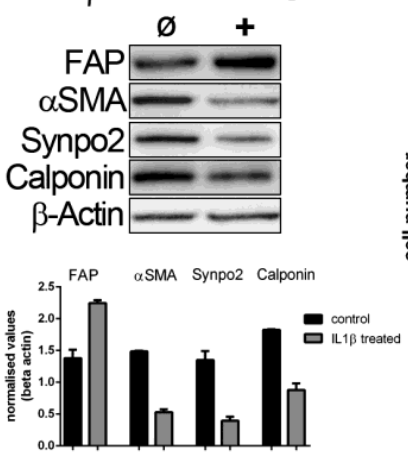

D
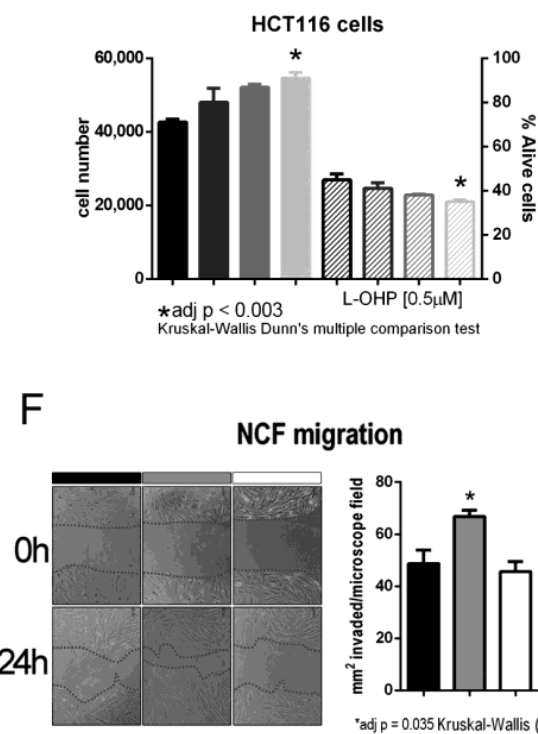

NCF migration

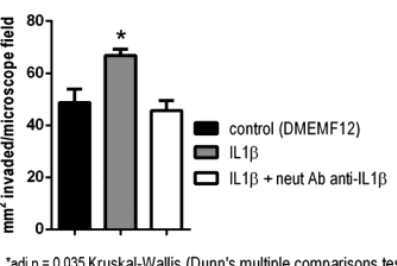

'adj $=0.035$ Kruskal-Wallis (Dunn's multiple comparisons test)

$\mathrm{H}$ directional migration NCFs

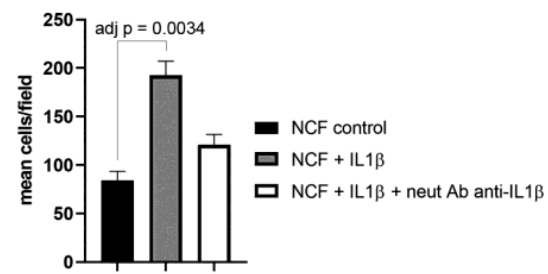

I
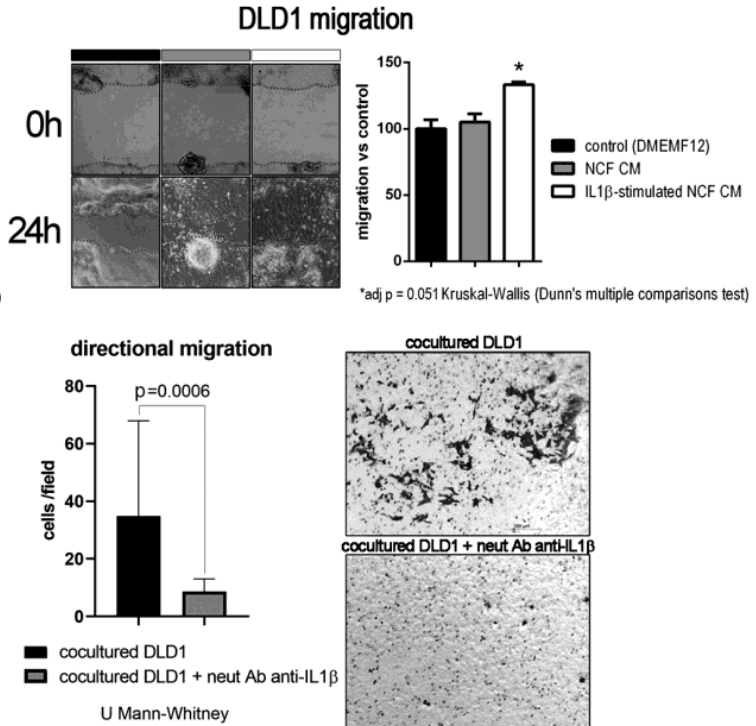

'adj p $=0.051$ Kruskal-Wallis (Dunn's multiple comparisons test)

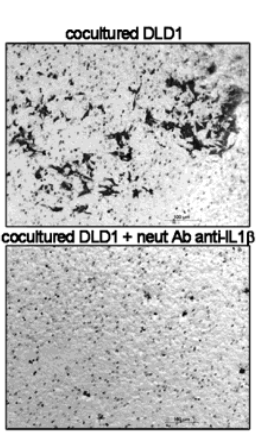

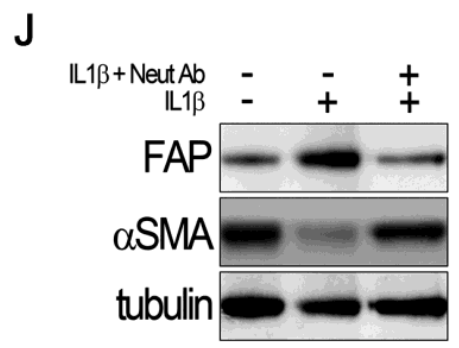

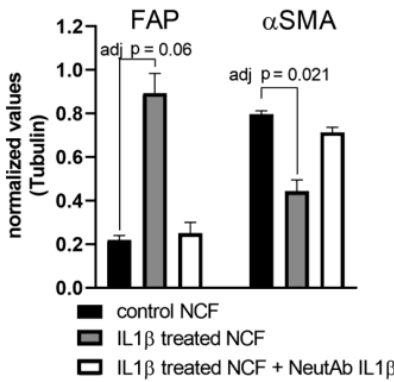

Figure 2. (A) Representative western blot of phenotypic changes observed in NCF stimulated with IL1 $\beta$. After $72 \mathrm{~h}$ IL1 $\beta$-stimulation $(10 \mathrm{ng} / \mathrm{mL}$ ) NCF myofibroblasts lose myofibroblastic markers ( $\alpha$ SMA, Calponin, Synpo2) and overexpress activated CAF marker fibroblast activating protein (FAP). The bar graph below depicted mean (plus standard deviation) normalized densities (using $\beta$-Actin as loading charge) for three independent western blot cell extracts, illustrating the decrease in myofibroblastic markers $\alpha$ SMA, Calponin, and Synaptopodin 2. (B) IL1 $\beta(10 \mathrm{ng} / \mathrm{mL})$ induced tumor cell 
proliferation in only two of the seven colorectal cancer cell lines. Bars depicted mean $+\mathrm{sd}$ of four independent experiments of three replicates each. (C) Conversely, IL1 $\beta$ induced proliferation of NCFs in a 5-day WST-1 assay. These values could be restored by the addition of a P38 inhibitor (VX-702, $400 \mathrm{nM})$ and a neutralizing polyclonal antibody against IL1 $\beta$ (2 $\mu \mathrm{g} / \mathrm{mL}$ ) (Kruskal-Wallis, Dunn's multiple comparison test; bars depicted mean + sd of four independent experiments of three technical replicates each). Selecting the cell lines that responded to (10 $\mathrm{ng} / \mathrm{mL})$ IL1 $\beta$, we checked the dose-response effect of IL1 $\beta$ on proliferation and survival against IC $_{50}$ values for oxaliplatin (L-OHP), observing a dose-response trend only in HCT116 cells (D). IL1 $\beta$ did not induce any protection against L-OHP. No effect was observed in HT29 cells (E). Both $\mathrm{D}$ and $\mathrm{E}$ represent mean values + sd of three independent experiments of six technical replicates each. Assaying the effect of IL1 $\beta$ on fibroblast migration revealed a statistically significant increase in migration induced by the interleukin (F). We reported the same observation when analyzing directional migration of fibroblasts $(\mathbf{H})$. This effect could be counterbalanced by the addition of a neutralizing polyclonal antibody against IL1 $\beta(2 \mu \mathrm{g} / \mathrm{mL})$. Bars displayed mean values $+\mathrm{sd}$ of three independent experiments. Conditioned media from IL1 $\beta$-stimulated NCFs induced the migration of tumor cells, both in a wound healing assay (G); white bar; bars displayed mean values + sd of three independent experiments; adj $p$ value = 0.051) and directional migration in transwell, seeding NCFs in the bottom chamber (I); $p=0.0006$, U Mann-Whitney test). (J) Representative western blot displaying that the blocking of IL1 $\beta$ with a polyclonal neutralizing antibody anti-IL1 $\beta$ (2 $\mu \mathrm{g} / \mathrm{mL}$ ) maintains the myofibroblastic phenotype in NCFs determined as the expression of $\alpha \mathrm{SMA}$ and the decrease of FAP. The bar graph shows the mean + sd for three independent experiments not reaching statistical significance for FAP $(p=$ 0.06 after adjusting for multiple comparison), but significant for $\alpha \mathrm{SMA}(p=0.021$, after adjusting for multiple comparison; Kruskal-Wallis plus Dunn's multiple comparison test).

\subsection{Chemoresistance Induced by IL1 $\beta$-Responsive Soluble Factors}

We checked the effect of IL1 $\beta$ using dose-response curve assays against increasing doses of L-OHP. Once again, only HT29 cells responded to IL1 $\beta$, inducing a significant shift in the $\mathrm{IC}_{50}$ curves for L-OHP (Figure 3A). None of the other CCCL were chemoprotected from L-OHP by IL1 $\beta$; however, we explored whether the secretion of IL1 $\beta$-responsive proteins into the medium, could be responsible for inducing a protective milieu for tumor cells, thereby increasing the viability of tumor cells. As illustrated in Figure 3B, IL1 $\beta$ stimulated NCF-CM stimulated proliferation of all the tumor cells tested (dark grey bars, left vertical axis in Figure 3B) but also promoted the viability of CRC cell lines exposed at fixed doses of L-OHP (dark grey bars, right vertical axis, Figure 3B; significant P values correspond to adjusted P values after Dunn's multiple comparison test). Interestingly, both proliferation and viability could be restored to the same levels as non-stimulated NCF-CM (black bars in Figure 3B) by the addition of an IL1 $\beta$-blocking antibody to the IL1 $\beta$-stimulated NCF cultures (light grey bars, Figure 3B). The observation was reproduced when assaying the protective effect of IL1 $\beta$ targets in a dose-response assay (Figure 3C, left panel), in which the blocking antibody neutralized the effect of IL1 $\beta$, thereby avoiding the secretion of IL1 $\beta$ targets into the CM, and restoring the $\mathrm{IC}_{50}$ values for L-OHP in DLD1 cells. In addition, the protective effect induced by fibroblast-secreted products was not restricted to stimulated NCFs since normal foreskin fibroblasts stimulated with IL1 $\beta$ yielded the same observation (Figure $3 \mathrm{C}$, middle and right graphs). We can not attribute such protective effect to a single IL1 $\beta$ target, since as described in Supplementary Figure S1, many of the assessed soluble factors are known chemoprotective cytokines and chemokines as IL6, IL8, CCL2 among others (Supplementary Data and Supplementary Figure S1). 

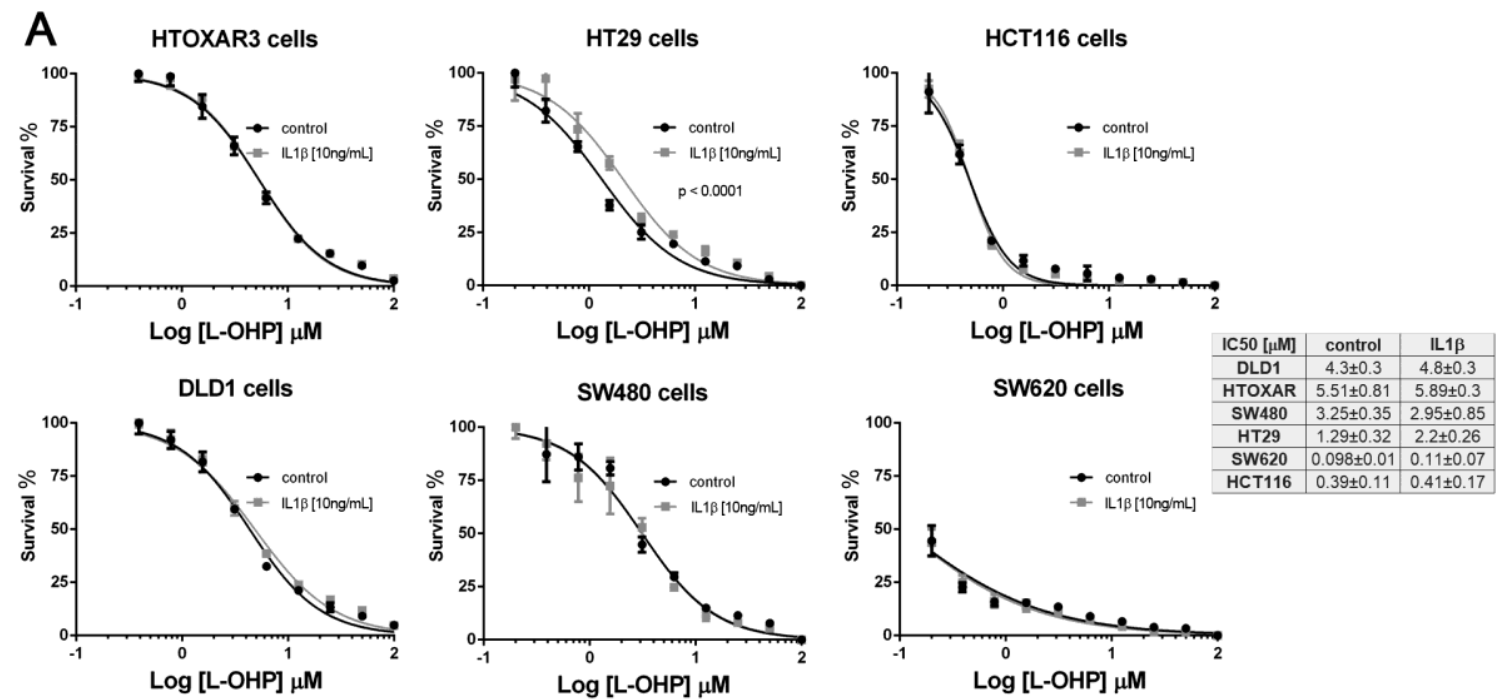

B
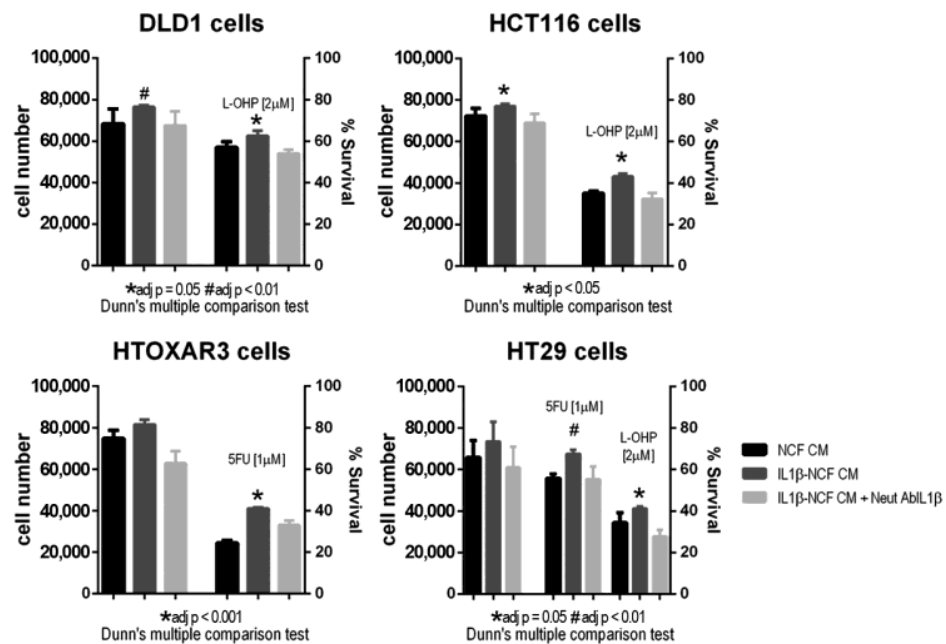

C
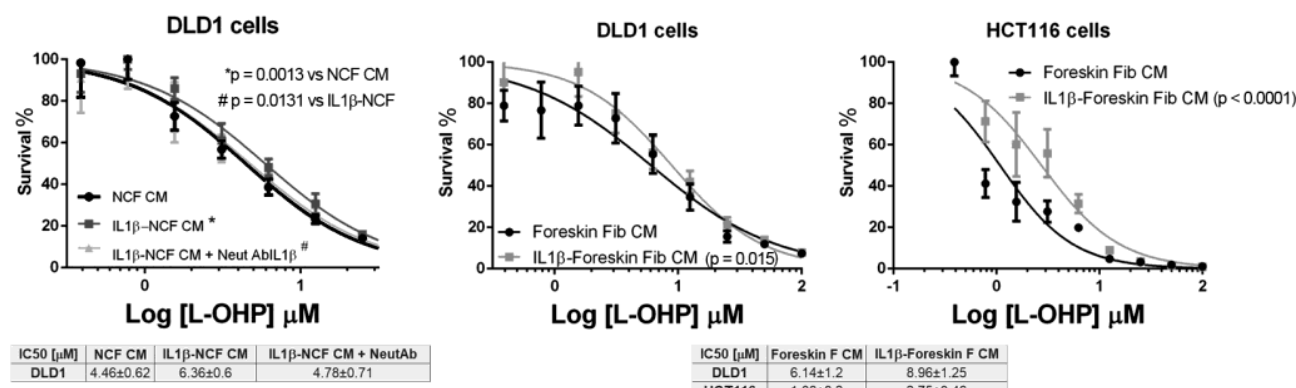

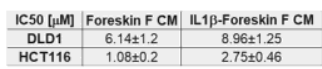

Figure 3. (A) Panel with dose-response curves for L-OHP of six colorectal cancer cell lines cultured under standard conditions (black lines) or in the presence of $(10 \mathrm{ng} / \mathrm{mL})$ IL1 $\beta$ (grey lines). IL1 $\beta$ displaced the IC 50 values for L-OHP only in HT29 cells. Each dose-response curve corresponds to the mean of three independent experiments of six technical replicates each. Differences between mean $(n=3)$ dose-response curves were compared with extra sum-of-squares F test $\left(\log \mathrm{IC}_{50}\right)$. Survival is reported as \%. (B) Panel of four colorectal cell lines treated with conditioned medium (CM) from NCFs (black bars), IL1 $\beta$-stimulated NCFs (dark grey bars), or IL1 $\beta$-stimulated NCFs plus a neutralizing antibody against IL1 $\beta((2 \mu \mathrm{g} / \mathrm{mL})$; light grey bars). IL1 $\beta$ used at $(10 \mathrm{ng} / \mathrm{mL})$. For all cell lines tested, IL1 $\beta$-stimulated NCFs CM promoted proliferation (left $\mathrm{Y}$ axis) of tumor cells, although the effect relative to control NCFs CM was only statistically significant in DLD1 and HCT116 cells. The right $Y$ axis shows that, for all cell lines and drugs (L-OHP and 5FU), the viability of cells cultured with IL1 $\beta$-stimulated NCFs CM was greater than that of controls (Kruskal-Wallis, Dunn's multiple comparison test, adjusted P values), meaning that IL1 $\beta$ targets modified the sensitivity to both drugs. Such sensitivity was restored by the addition of a neutralizing IL1 $\beta$ antibody during NCF culture for CM production. Bars depicted mean + sd of four independent experiments of six technical replicates each. (C) The same observation as described in (B), in dose-response 
curves, where IL1 $\beta$-stimulated $(10 \mathrm{ng} / \mathrm{mL})$. NCFs CM induced a shift in the $\mathrm{IC}_{50}$ curves for L-OHP, leading to an increase in tolerance of cytotoxic compounds (left plot). Similar results were obtained for DLD1 and HCT116 using foreskin fibroblasts (middle and right graphs). Survival is reported as \%. In both cases, dose-response curves correspond to the mean of three independent experiments.

To demonstrate that the crosstalk between tumor cells and fibroblasts mediated by IL1 $\beta$ induces chemoresistance, we performed a colony forming assay in transwell cocultures between different CCCL (700 cells per well; lower chamber) and NCF (50,000 cells, $24 \mathrm{~mm}$ inserts $0.4 \mathrm{~nm}$ pore size), with the addition of L-OHP. To hamper the action of IL1 $\beta$, a blocking IL1 $\beta$ antibody had been added to the test group. After 10 days in coculture we stained the lower chambers with crystal violet. As depicted in Figure 4A,B, cocultures with the addition of the neutralizing antibody displayed a smaller number of colonies for all the cell lines tested. To evaluate the effectiveness of the addition of the blocking antibody, we assessed the presence of free IL1 $\beta$ in the coculture pooled supernatant (equal volumes from cocultures with DLD1, HCT116, or HT29), as well as IL6, as a surrogate marker of the IL1 $\beta$ response, observing that the addition of the neutralizing antibody blocked both IL1 $\beta$ and IL6 (Figure 4C).

As expected, most of the IL1 $\beta$ targets stimulated JAK/STAT and AKT pathways in tumors cells. This activation can be reversed by neutralizing the binding of IL1 $\beta$ to their receptors in NCFs (Figure 4D). In addition, CM from IL1 $\beta$-treated fibroblasts induces the overexpression of Cyclin D1 and cMyc, which might help explain how IL1 $\beta$-soluble targets influence the cell-cycle progression and chemoresistance observed in tumor cells, when treated with L-OHP (Figure 4E).

To find out if the source of IL1 $\beta$ that stimulate the fibroblasts in a paracrine form could be the interleukin generated by the tumor cells, we silenced the expression of IL1 $\beta$ in the HT29 cells (Supplementary Figure S2). Thus, if the tumor cells, in response to soluble factors of the NCFs, could not secrete IL1 $\beta$, the fibroblasts would not respond with the secretion of cytokines that altered the damage induced by the chemotherapy (experiment overview in Figure 4F). Therefore, the conditioned media generated from IL1 $\beta$-silenced HT29 cells and fibroblasts cocultures, when used to stimulate HT29 cells in a dose response assay against L-OHP, protected to a lesser extent against the drug (Figure 4G, light grey line), compared to conditioned media from cocultures obtained with wild-type and nonsilenced (mock) HT29 cells and fibroblasts. The exogenous addition of recombinant IL1 $\beta$ to the IL1 $\beta$-silenced HT29 cocultures restored the IL1 $\beta$ targets, and consequently the IC 50 values of HT29 cells to L-OHP (Figure 4E). Likewise, when we explored the effects of IL1 $\beta$ silenced tumor cells on co-cultured NCFs, we could observe that cocultured fibroblasts lost the expression of inflammatory cytokines, as IL6, LIF or CCL2, while acquired markers of myofibroblasts (ACTA2, PDPN, MYH11, or CNN1; Figure 4H). 

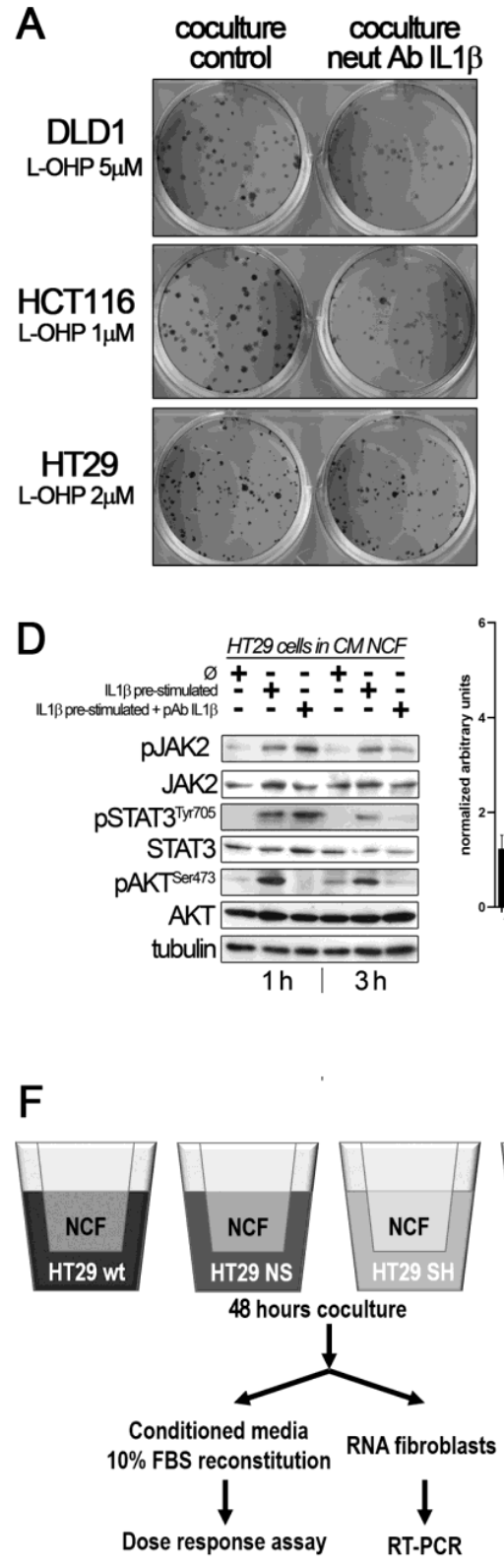

B
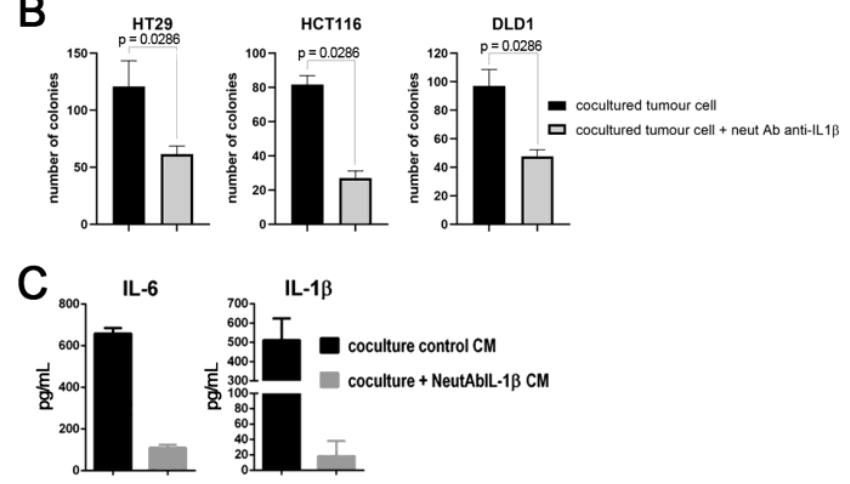

E

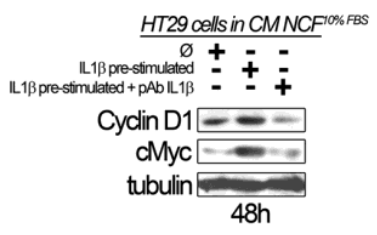

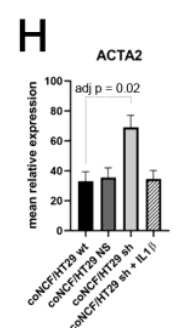
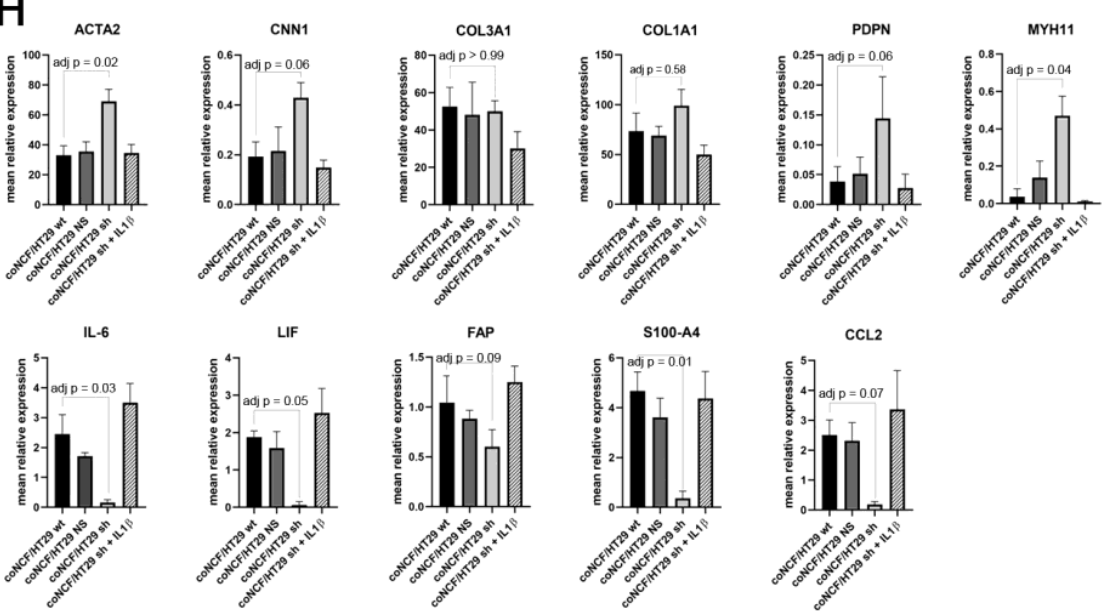

Figure 4. (A) colony forming assay of CCCL in transwell coculture with NCF. (B) quantification of colonies: Blocking the IL1 $\beta$-mediated crosstalk between cocultures of NCF (upper $24 \mathrm{~mm}$ transwell chamber) and colorectal cancer cell lines (lower transwell chamber) with a neutralizing IL1 $\beta$ antibody sensitizes cancer cells to L-OHP. (C) Such IL1 $\beta$ blocking altered the 
composition of conditioned media (affecting IL1 $\beta$ targets), as illustrated in the bar graphs, where the neutralizing antibody affected the IL1 $\beta$ itself and IL6, as a surrogate marker of the IL1 $\beta$ response (grey bars), both soluble factors determined by ELISA in a mixture of coculture supernatants before 10\% FBS reconstitution (proportional volume of the different CM from NCF with either DLD1, HT29, or HCT116 cells). (D) Western blot of HT29 cells cultured with control CM (Ø) or IL1 $\beta$-stimulated NCF-conditioned medium $(10 \mathrm{ng} / \mathrm{mL}$ of IL1 $\beta)$ or same condition with the addition of a polyclonal neutralizing antibody against IL1 $\beta(2 \mu \mathrm{g} / \mathrm{mL})$. FBS-free DMEM/F12 was used to generate conditioned medium after 48 $\mathrm{h}$ NCFs culture with or without the presence of the neutralizing antibody. Such conditioned media were then used to stimulate JAK2, STAT3, or AKT in HT29 cells for $1 \mathrm{~h}$ or $3 \mathrm{~h}$. Quantification of phosphoproteins for three independent experiments was performed normalizing first for total JAK2, STAT3, or AKT and then normalizing for Tubulin (data expressed as arbitrary units). Statistical significance was assessed using non-parametric Kruskal-Wallis + Dunn's multiple comparison test. (E) In $48 \mathrm{~h}$ experiments, the same conditioned media were reconstituted at $10 \%$ FBS. We evaluated JAK/STAT target proteins, Cyclin D1, and cMyc. (F) Overview of the experiment: to confirm paracrine signaling mediated by tumor cell-derived IL1 $\beta$, we cocultured NCFs and HT29 cells with a defective secretion of IL1 $\beta$, (silenced by means of shRNA) or transfected with a mock vector or wild-type as controls ( $75 \mathrm{~mm}$ transwell inserts, $3 \mu \mathrm{m}$ pore-size). As a positive control, we added IL1 $\beta$ to cocultures with HT29-shIL1 $\beta$ and NCFs. Culture conditions were: $2 \times 10^{6}$ cells tumor cells in the lower chamber and fibroblasts in the upper chamber $\left(10^{6}\right.$ cells) in FBS-free DMEMF12. After $48 \mathrm{~h}$, we harvested the conditioned medium and reconstituted the 10\% FBS. As illustrated in (G), the conditioned medium obtained from cocultured NCFs and IL1 $\beta$-deficient tumor cells (Ht29shIL1 $\beta$ ) yielded lower IC $_{50}$ values in dose-response assays compared with the other experimental conditions tested ( $p<0.0001$; survival is reported as $\%$ ). The conditioned media obtained from

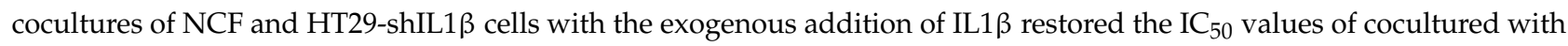
HT29 wild-type cells. Each dose-response curve corresponds to the mean of three independent experiments of six technical replicates each. Differences between dose-response curves were compared with extra sum-of-squares $\mathrm{F}$ test (Log IC $\left.\mathrm{L}_{50}\right)$. (H) Real-Time PCR of the aforementioned cocultured NCF's reported that the inhibition of the IL1 $\beta$-mediated crosstalk between HT29shIL1 $\beta$ cells and fibroblasts induced a myofibroblastic phenotype in NCFs, with increased expression of ACTA2, CNN1, PDPN, and MYH11, while inflammatory markers were diminished, evidenced by decrease in IL6, LIF, and CCL2 (Kruskal-Wallis test; adjusted P values after Dunn's multiple comparison test).

This fact, together with observations in Figure 2A,J let us to hypothesize that perhaps the population of inflammatory CAFs could be responsible of altering the chemosensitivity against cytotoxic drugs like L-OHP, while myofibroblastic CAFs might have other functions. To test this, we stimulated NCFs with $(10 \mathrm{ng} / \mathrm{mL})$ IL1 $\beta$ or $(20 \mathrm{ng} / \mathrm{mL})$ TGF $\beta 1$ for $48 \mathrm{~h}$. With the conditioned media we performed a dose-response assay against L-OHP in CCCL. As illustrated in Figure 5A, only the IL1 $\beta$-stimulated NCFs CM increased the L-OHP IC 50 values (Fisher test; $p<0.0001$ ), while the TGF $\beta 1$-stimulated NCFs CM did not differed from the NCF CM control, both in DLD1, HT29, and HCT116 cells. Similar results were observed in a colony forming assay, where IL1 $\beta$-treated NCF conditioned medium significantly avoided the reduction of colonies induced by $5 \mu \mathrm{M}$ and $10 \mu \mathrm{M}$ L-OHP than TGF $\beta 1$-treated NCF conditioned medium $(\operatorname{adj} p=0.013$ and adj $p=0.005$, respectively; Kruskal-Wallis test with Dunn's correction for multiple comparison; Figure 5B).

Real-Time PCR assessment of CAF's markers on treated NCF shows that, in response to IL1 $\beta$ there is a statistically significant increase of FAP, IL1 $\beta$, IL6, and CCL2, markers associated with an inflammatory CAF phenotype (iCAF), being all the cytokines tested involved with the induction of chemoresistance-associated pathways. TGF $\beta 1$-treated NCFs displayed, as expected, a more myofibroblastic phenotype. However, CLEC3B and GSN, genes reported to be markers for $\mathrm{iCAF}$, were expressed as TGF $\beta 1$ targets (CLEC3B) or no difference between both stimulations (GSN). 
A
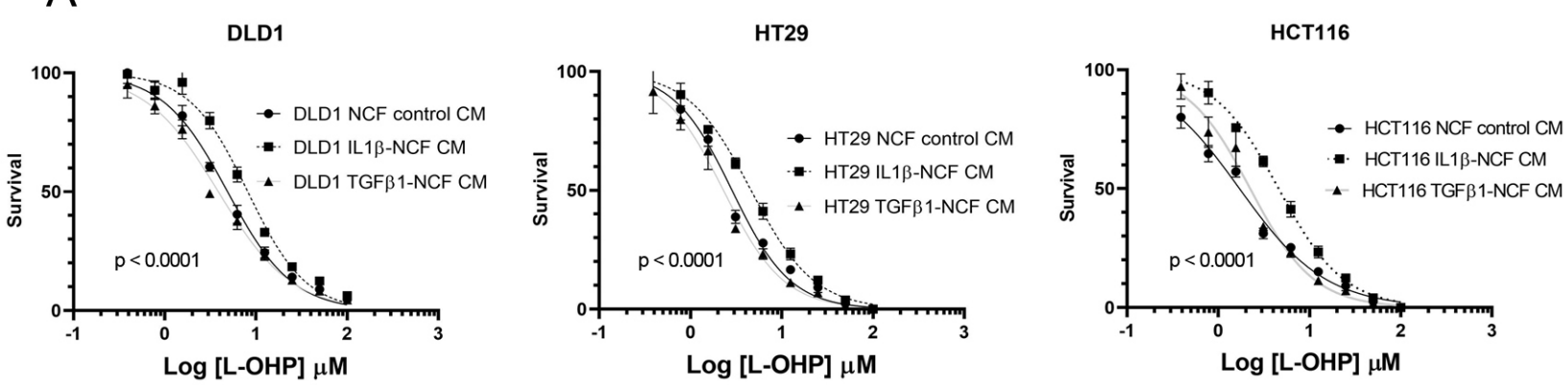

\begin{tabular}{|c|c|c|c|}
\hline IC50 $[\mu \mathrm{M}]$ & DLD1 & HT29 & HCT116 \\
\hline NCF control CM & $4.89 \pm 0.3$ & $2.83 \pm 0.25$ & $1.71 \pm 0.11$ \\
\hline IL1 $\beta$-NCF CM & $8.16 \pm 0.5$ & $4.61 \pm 0.3$ & $4.59 \pm 0.35$ \\
\hline TGF $\beta 1-N C F$ CM & $3.87 \pm 0.6$ & $2.29 \pm 0.16$ & $2.22 \pm 0.21$ \\
\hline
\end{tabular}
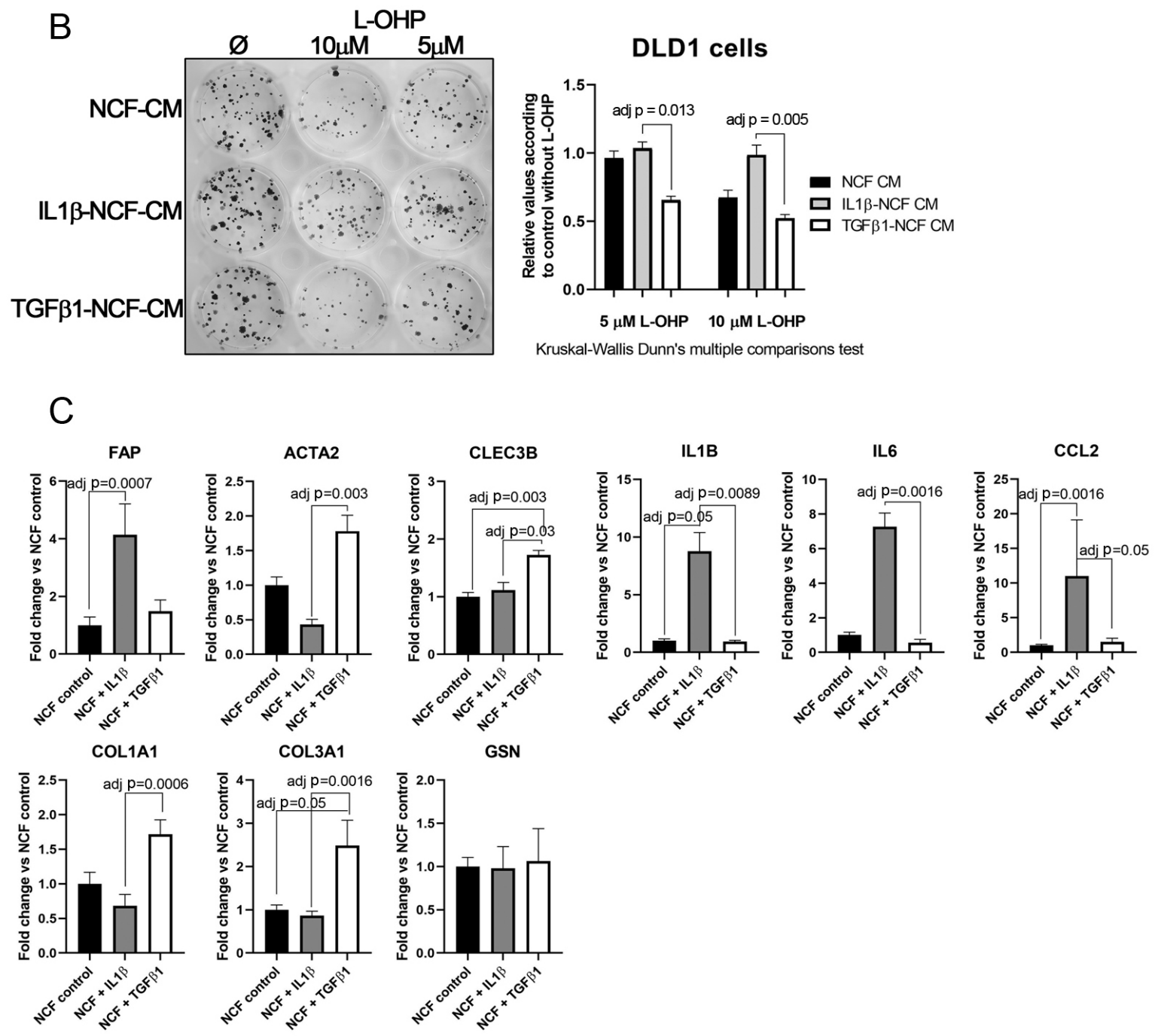

Figure 5. (A) Dose-response curves of L-OHP treated DLD1, HT29, and HCT116 cells cultured in NCF control conditioned media, IL1 $\beta$-stimulated NCF conditioned media or TGF $\beta 1$-stimulated NCF conditioned media. For all cell lines tested, IL1 $\beta$-treated NCFs conditioned media induced an increase in the $\mathrm{IC}_{50}$ values against L-OHP, while values for TGF $\beta 1$-treated NCFs media did not differ from NCF control conditioned media. Each dose-response curve corresponds to the mean of three independent experiments of four technical replicates each. Differences between dose-response curves were compared with extra sum-of-squares $\mathrm{F}$ test (Log $\mathrm{IC}_{50}$ ). (B) Colony forming assay of DLD1 cells (seeding density, 400 cells in twelve-well 
plates). We cultured cell lines with the aforementioned conditioned media in the presence of two different L-OHP concentrations. The quantification of the colonies reported that IL1 $\beta$-treated NCFs conditioned media produced more colonies than TGFß1-treated NCF's conditioned media (Kruskal-Wallis test plus Dunn's multiple comparison test, adjusted $P$ values). (C) The expression values of different iCAF and myCAF markers were assessed by means of quantitative PCR in treated NCFs, showing that IL1 $\beta$ treated fibroblast acquired traits of iCAF, with the exception of CLEC3B and GSN, genes attributed to iCAFs in different publications [20]. Results expressed as fold changes in relation to normalized control.

\section{Discussion}

The interplay between tumor cells and their neighboring normal cells occurs even at early stages of tumorigenesis, when few transformed epithelial cells interact with pericryptal myofibroblasts. These fibroblasts play an important role in regulating the normal colorectal stem cell niche, controlling normal tissue homeostasis and facilitating tumor progression when homeostasis is lost [21], and is probably the main source of CAFs after appropriate stimulation.

A wide range of cytokines, growth factors have been reported as having a role in the differentiation of fibroblasts into myofibroblasts, like TGF $\beta 1$ [22], PDGF $\beta$ [23], IL13 [24], etc. Conversely, IL1 $\beta$ has been described as inhibiting myofibroblast differentiation, decreasing the levels of $\alpha \mathrm{SMA}$ and other contractile proteins [25]. Nevertheless, the role of IL1 $\beta$ in the context of the differentiation of myofibroblasts to CAFs has been less thoroughly studied, particularly with respect to the CAF subtypes in which differential $\alpha$ SMA expression has recently been reported [26,27].

IL-1 expression is elevated in several human cancers, and patients with tumors that express IL-1 generally have a worse prognosis for their disease. In fact, the involvement of IL-1 and particularly IL1 $\beta$ in proliferation, invasion and metastasis has long been known. Two studies in animals in the early 1990s showed that a single dose of IL-1 administered just before the intravenous injection of tumor cells increased the number of lung metastases $[28,29]$. Paracrine crosstalk mediated by tumor-derived IL1 $\beta$ and CAFs was also described [12]. Moreover, such crosstalk seems to be very important in incipient neoplasia to orchestrate tumor-promoting inflammation [30]. However, the involvement of IL1 $\beta$, particularly tumor cell IL1 $\beta$ crosstalk with normal resident myofibroblasts, either at a primary site (NCFs) or at a distant niche (NHFs), altering the sensitivity to cytotoxic chemotherapy has not been described. Here, we report a IL1 $\beta$-mediated paracrine loop from tumor cells towards normal resident fibroblasts, that elicits a secretory response in fibroblasts that increases the tolerance of tumor cells to L-OHP and might be responsible for the pool of the iCAFs subset. Such a process might be altered by the addition of an IL1 $\beta$ blocking agent, rendering tumor cells without the protection conferred by fibroblast-soluble factors, and avoiding NCF-to-CAF conversion.

The autocrine role of IL1 $\beta$ in inducing chemoresistance in pancreatic cancer cells was first demonstrated in 2002 [31]. In our experiments, we did not observe any direct action of IL1 $\beta$ on tumor cells, similar to results published by Young $\mathrm{H}$ et al. [32] for BRAF and MEK inhibitors. We concluded that IL1 $\beta$ did not by itself induce resistance to conventional drugs used in CRC treatment. In fact, we have shown how IL1 $\beta$ secreted by cancer cells is used to educate surrounding normal resident fibroblasts to create a niche that first induces the recruitment of fibroblasts (enhanced migration) and their proliferation, and then helps tumor cells to overcome the damage induced by chemotherapeutic cytotoxic agents, such as L-OHP and 5-fluorouracyl. In this context, this crosstalk contributes to induce a certain tolerance to chemotherapy-induced damage, a transient protection, until the tumor cells are capable of developing resistant phenotypes. This fact is not limited to chemotherapeutic drugs since a similar crosstalk induced by macrophage-derived IL1 $\beta$ that generates tolerance to BRAF and MEK inhibitors has been published [32]. In particular, these authors observed that IL1 $\beta$ secreted by cancer-associated macrophages induced the secretion of CXCR2 ligands by CAFs, such as IL8 and GRO $\alpha$ (CXCL1), which were ultimately the mediators of such tolerance in tumor cells. In fact, IL8, CXCL1, along with 
IL6 and CCL2, are the most represented soluble molecules in the conditioned media of IL1 $\beta$-treated NCF, out of the 174 tested molecules (Supplementary Figure S1).

It is also of particular note that, in the context of the recently described coexistence of different CAF subpopulations [27,33,34], IL1 $\beta$ seems to downregulate the myofibroblastic phenotype to potentiate the FAP-positive inflammatory phenotype (iCAF), a process that could be avoided by blocking the action of IL1 $\beta$. Thus, in an indirect process, IL1 $\beta$ gives rise to the differential sensitivity of CRC cancer cells.

To examine the signaling events that occur in tumor cells after stimulation by $\mathrm{CM}$, we set our sights on signaling pathways in which we had previously observed involvement in de novo resistant processes [35]. As expected, IL1 $\beta$-soluble targets mentioned above, like IL8, IL6, and CCL2, activated the JAK/STAT and PI3KCA/AKT pathways. Hindering the interplay between IL1 $\beta$ and its receptors in myofibroblasts renders these cells less active and less proficient at secreting protumoral and chemoprotective cytokines and growth factors. In turn, tumoral cells showed decreased levels of activation in both pathways. This raises the possibility of using anti-IL1 $\beta$ agents as a coadjuvant treatment in combination with cytotoxic drugs to avoid environmentally mediated drug-resistant processes. Furthermore, blocking IL1 $\beta$ might help in the clinical control of therapy-induced inflammation that could impede the effectiveness of chemotherapy [36]. In fact, the utility of canakinumab (anti-IL1 $\beta$ monoclonal antibody) has been explored in two clinical trials in solid tumors (NCT03447769, NCT02900664). Other agents used to treat rheumatoid arthritis, like anakinra (an IL1-receptor antagonist), have been repositioned as an anticancer treatment in PDAC, metastatic CRC (NCT02550327, NCT02090101).

Our results, in the context of colorectal cancer management, suggest a way of increasing the response rate to the neoadjuvant treatment in rectal cancer, the only CRC setting in which primary tumors are treated before surgery. This might help to restrain the local tumor's growth, avoiding paracrine signals from the localized tumor to adjacent tissue and then blocking tumor-induced and therapy-induced proinflammatory signals that favor chemoresistance. In fact, it has recently been demonstrated that normal adjacent colonic tissue can predict prognosis in colorectal cancer [37]. Such an aberrant transcriptomic profile of supposedly normal tissue is the consequence of the crosstalk with the tumor [38]. However, it is unclear what is activating what. In other words, which factor causes the tumor cells' increased expression of IL1 $\beta$ ? This question, for the moment, is difficult to answer. We explored CCL11 and CCL2, the two most highly expressed cytokines of the 174 soluble factors tested, by NCFs under basal conditions. Neither of them caused overexpression of IL1 $\beta$ in CRC cell lines. Other less well represented soluble factors, or a combination of different cytokines and growth factors, might be the trigger.

In recent years there has been an explosion in terms of the appearance of countless scientific articles describing different CAFs subsets [20,39,40], although most of them could be summarized in two main classes, pro-inflammatory iCAFs and others with a purely myofibroblastic profile, myCAFs, characterized by the production of collagens and other proteins of the extracellular matrix. The protumoral or antitumor role of each of these subsets described is not clear. Both, IL1 $\beta$ and TGF $\beta 1$, along with some more soluble factors, have been described to be molecules that mediate the crosstalk between tumor cells and fibroblasts and are responsible for the activation state of the latter [22,41]. However, different ligands will induce different CAF subsets. Recently it has been described that IL1 $\beta$ and TGF $\beta 1$ appear to act antagonistically [42]. This fact contributes to the plasticity of fibroblasts depending on their topographic location as the tumor modifies its shape with growth. However, our results contribute to elucidate which subset is more suitable to be eliminated or modified therapeutically, since iCAFs can contribute to the development of chemotherapy-resistant phenotypes. In any case, we must be cautious in this regard since it has been shown that the use of JAK inhibitors to attenuate the pro-inflammatory response has increased the proportion of myofibroblasts, with the consequent increase in extracellular matrix deposits, which end up hindering the access of chemotherapy into the tumor $[43,44]$. This fact would support the strategy of combining an anti-iCAF 
treatment together with modulation of the action of TGF $\beta 1$, in a similar way to what our group published a few years ago by combining a TAK1 inhibitor in combination with Galunisertib [41].

In summary, the soluble factors produced by normal colonic fibroblasts in response to IL1 $\beta$ generate chemoresistance in CRC cells, while they do not produce such an effect in response to TGF $\beta 1$. Hindering IL1 $\beta$-mediated crosstalk between fibroblasts and tumor cells might counteract inflammatory signaling, causing de novo resistance. This raises the possibility of using anti-IL1 $\beta$ to prevent such tumor-mediated and therapy-induced proinflammatory events that sensitize tumors to chemotherapy. Such agents, in combination with anti-TGF $\beta 1$ therapies, might block the recruitment of new fibroblasts into the growing tumor, helping to restrain the cancer and avoid new stroma activation.

\section{Methods}

\subsection{Culture of Primary Fibroblasts and Preparation of Conditioned Medium (CM)}

Fresh surgical specimens were obtained with the approval of the Ethics Committee of the Hospital Universitari de Bellvitge (IDIBELL), under patient's informed consent (approval reference PR91/10, IDIBELL Ethics Committee, 6 May 2010). Tissue samples from morphologically normal colonic mucosa (at least $5 \mathrm{~cm}$ from the tumor's surgical margin), primary tumors and normal liver (at least $5 \mathrm{~cm}$ from the resected liver metastasis) were minced and incubated with collagenase (Stemcell technologies, Saint Égrève, France) and dispase $(1 \mathrm{U} / \mathrm{mL}$ in DMEM/F12; Stemcell technologies, Saint Égrève, France) for $2 \mathrm{~h}$ at $37^{\circ} \mathrm{C}$. Cells were resuspended and plated with Dulbecco's modified Eagle's medium-F12 (DMEM/F12, Gibco, Life Technologies, Oslo, Norway) containing 10\% fetal bovine serum (FBS; Gibco, Life Technologies, Oslo, Norway) and penicillin/streptomycin antibiotics. Primary cultures from normal colonic fibroblasts (NCFs), paired CAFs, or normal hepatic fibroblasts (NHFs) were established and routinely maintained at $37^{\circ} \mathrm{C}$ in a humidified atmosphere containing $5 \% \mathrm{CO}_{2}$. After a maximum of 4 passages, RNA and protein were obtained to check for fibroblast purity. To obtain conditioned media (CM), $10^{6} \mathrm{NCF}$ were incubated for $48 \mathrm{~h}$ in $10 \mathrm{~cm}$ diameter dishes in DMEM/F12 or DMEM/F12 + IL1 $\beta$ (10 ng/mL). CM was collected, centrifuged for $5 \mathrm{~min}$ at $3000 \mathrm{rpm}$ to remove cell debris, sterile-filtered through $0.22-\mu \mathrm{m}$ filter units (Millex ${ }^{\circledR} \mathrm{GS}$, Millipore), and stored at $-80{ }^{\circ} \mathrm{C}$ until use.

\subsection{Colorectal Cancer Cell Lines}

DLD1, LoVo, Colo-205, RKO, Co115, HCT-15, KM12C, Caco-2, HCT116, HT-29, SW480, SW620, and SW1116 were all cultured in 10\% FBS DMEMF12. Cells were periodically tested for mycoplasma contamination and were authenticated by short tandem repeat profiling. For functional assays, we have used the most appropriate cell lines in each particular experiment for the correct visualization and execution of the designed objectives in concordance with our previous experience with the aforementioned cell lines.

\subsection{Cocultures of NCFs with Colorectal Cancer Cell Lines (CCCL)}

Isolated NCFs were cocultured with DLD1 cells for 5 days in 6-well transwell inserts $3 \mu \mathrm{m}$ pore-size. After coculturing, total RNA was extracted for IL1 $\beta$ mRNA quantification by qRT-PCR. Unless stated, fibroblasts were plated in the lower chamber $\left(10^{5}\right.$ cells $)$ and tumor cells in the upper chamber of the insert $\left(10^{4}\right.$ cells $)$.

In specific co-culture experiments, HCT116 and HT29 were also used.

\subsection{RNA Isolation and Quantitative Real-Time PCR (qRT-PCR)}

Total RNA from different isolated fibroblasts and CCCL was extracted using the TRIzol $^{\circledR}$ reagent method and column purification using PureLink ${ }^{\mathrm{TM}}$ RNA Mini Kit (Invitrogen, Van Allen Way, Carlsbad, California 92008, USA). RNA quantity was determined with a NanoDrop ND-1000 spectrophotometer (NanoDrop Technologies Inc., Rockland, DE, USA) and 100ng of total RNA was reverse-transcribed using M-MLV reverse tran- 
scriptase (Invitrogen), following the manufacturer's instructions. A 0.1- $\mu$ g equivalent of the corresponding cDNA was used for each quantitative PCR assay performed with the LightCycler ${ }^{\circledR} 480$, SYBR Green I Master (Roche Applied Science, Mannheim, Germany). Primers for IL1 $\beta$, IL1R1, IL1R2, ACTA2, FAP, IL6, COL3A1, COL1A1, MYH11, PDPN, S100A4, CCL2, CNN1, LIF, CLEC3B, and GSN were designed using Primer3 Input (https: / / primer3.ut.ee/, accessed on 12 June 2019), and predicted PCR product sequences were verified using BLAST (http://www.ncbi.nlm.nih.gov/blast, accessed on 12 June 2019). For all genes tested, annealing temperature was $60^{\circ} \mathrm{C}$ and 40 cycles were performed. All primer sequences are available upon request. In all cases, GAPDH was used for normalizing expression values.

\subsection{Cell Proliferation and Viability}

The WST-1 proliferation assay was performed following the manufacturer's instructions (Roche). Previously, 2000 cells/well (CCCL) or 20,000 cells/well (fibroblasts) were plated in six replicative wells in 96-well plates and allowed to attach, then grown in DMEM/F12 at $37{ }^{\circ} \mathrm{C}$ overnight. Next day, treatments were added accordingly, depending on which specific experiments, detailed in the corresponding figure legends, were to be carried out. The cells were incubated for 5 days. When cells were treated in dose-response curves against (L-OHP), the effect of the drug on each cell line in the presence or absence of $\mathrm{CM}$ or IL1 $\beta$ was calculated by normalizing the number of cells after 5 days of continuous treatment to the maximum number of cells in each treatment.

\subsection{Wound-Healing Assay and Directional Migration}

Migration of cancer cells and CAFs was measured by a wound-healing and transwell assays. For wound-healing, cells were seeded in 6-cm diameter plates and cultured until confluent. Cells were starved for $24 \mathrm{~h}$, and then the cell monolayer was scratched with a yellow 200- $\mu \mathrm{L}$ pipette tip to create a wound. After several PBS (phosphate-buffered saline $1 \times$ ) washes to remove floating cells, for the DLD1 cell migration assay, FBS-free conditioned medium from NCF or IL1 $\beta$-treated NCF or DMEM/F12 (control) was added. For the NCF migration assay, IL1 $\beta(10 \mathrm{ng} / \mathrm{mL})$ or IL1 $\beta$ plus IL1 $\beta$ neutralizing antibody (R\&D Systems AF-201-NA) were added $(2 \mu \mathrm{g} / \mathrm{mL}$ ). Pictures were taken at different times. The area between cell front margins was measured with Leica software (Wetzal, Germany) in three replicates. For directional migration, transwell PET inserts $(12 \mathrm{~mm}, 8 \mu \mathrm{M}$ pore size) were used. For NCF migration, $10^{4}$ cells were plated in the upper chamber. After twelve hours, FBS was removed and IL1 $\beta$ or anti-IL1 $\beta$ neutralizing antibody was added accordingly. For tumor cell migration in coculture, confluent NCFs were grown in the lower chamber and $5 \times 10^{3}$ DLD1 cells were plated in the upper chamber. Anti-IL1 $\beta$ neutralizing antibody was added in the test group wells. After $24 \mathrm{~h}$, cells were stained with crystal violet and transwell membranes were mounted on slides. Four microphotographies were taken for well and cells were counted manually with imaging software.

\subsection{Silencing IL1 $\beta$ by Lentiviral shRNA}

GIPZ lentiviral shRNA (cat \#V3LHS_321411 and \#V3LHS_321412 clones purchased from Dharmacon; Lafayette, CO, USA) was used to establish IL1 $\beta$ knockdown in HT29 colorectal cell lines. Glycerol-stored plasmid was previously replicated, isolated, transfected in HEK293T cells, and finally, transduced in target cells. Cells were selected with puromycin $(2 \mu \mathrm{g} / \mathrm{mL})$, according to kill curve values. A non-silencing GIPZ lentiviral shRNA containing a random vector was used as a control in subsequent experiments. Real-time PCR was performed to confirm IL1 $\beta$ silencing efficiency in HT29 cells.

\subsection{Cytokines and Chemicals}

Human recombinant IL1 $\beta$ and TGF $\beta 1$ were purchased from Peprotech (ref 200-01B, lot 1202B95R1 and 100-21C lot 0312354-1, respectively) and always used at (10 ng/mL) and $(20 \mathrm{ng} / \mathrm{mL})$, respectively. Neutralizing antibody against IL1 $\beta$ was purchased from R\&D 
Systems (reference AB201-NA, lot AM1311041). VX-702 (P38 inhibitor) was purchased from Selleck Chemicals (Houston, TX, USA) and dissolved in DMSO as a stock solution and used at $(400 \mathrm{nM})$. L-OHP was obtained from our own hospital Pharmacy Department in $5 \mathrm{mg} / \mathrm{mL}$ vials and diluted at working dilutions with sterile water.

\subsection{Western Blot Analysis}

Protein concentration was determined by the BCA Protein Assay (Pierce, Rockford, IL, USA). $30 \mu \mathrm{g}$ of the protein extract was subjected to sodium dodecyl sulfate polyacrylamide gel electrophoresis (SDS-PAGE) and transferred to PVDF membranes. After blocking for $1 \mathrm{~h}$ with 5\% dried non-fat milk in TBS $1 \times$ Tween $0.1 \%$ (or 5\% BSA for phosphoproteins), the membranes were incubated with primary antibody (all obtained from Cell Signaling Technology, Danvers, MA, USA, except $\alpha$ SMA, Dako M0851, FAP, SCBT sc-100528, Calponin SCBT sc-58707, Synpo2 Sigma HPA030665) diluted 1:1000 in 1\% bovine serum albumin (BSA) in TBS $1 \times$ Tween $0.1 \%$. Antibody binding was detected using a secondary antibody diluted 1:2000 in TBS $1 \times$ Tween $0.1 \%$ and an enhanced chemiluminescence (ECL) detection kit (Amersham plc, Amersham, Buckinghamshire, UK). $\alpha$-tubulin expression was used as an endogenous control.

\subsection{Cytokine Arrays and ELISA}

CM (1\% FBS) from NCF or IL $\beta$-treated NCF or IL1 $\beta$-treated NCF plus neutralizing IL1 $\beta$ antibody was used for hybridization on the glass-slide human cytokine array G2000 from RayBiotech (Norcross, GA, USA), which detects 174 human cytokines. Samples were processed and analyzed by Tebu-Bio (Le Perray-en-Yvelines, France).

IL6 and IL1 $\beta$ were determined in supernatants obtained from cocultures CM by means of ELISA (R\&D cat number D6050 and DLB50, respectively).

\subsection{Statistical Analysis}

Data from four independent experiments were analyzed using the nonparametric two-sided Mann-Whitney U test to compare group differences between experimental and control samples, with significance being concluded for values of $p<0.05$. In experiments with three or more groups, comparisons were made with the Kruskal-Wallis test and Dunn's multiple comparison test reporting adjusted $\mathrm{P}$ value after multiple testing. Bar graphs depicted mean values plus standard deviation. In dose-response curves, an extra sum-of-squares F test was carried out in GraphPad PRISM 8 (GraphPad Software, San Diego, California, USA) to identify statistically significant differences $(p<0.05)$ between $\mathrm{IC}_{50}$ curves. Sample size calculation was estimated using the web tool https:/ /www.imim. es / ofertadeserveis / software-public/granmo/ (accessed on 7 May 2021), using type I alpha error of 0.05 , two-tailed test, and beta error 0.2 .

Supplementary Materials: Supplementary materials are available online at https://www.mdpi. com/article/10.3390/ijms22094960/s1.

Author Contributions: Conceptualization, D.G.M.; methodology, N.G.D.-M., G.G.-V., G.P., N.A., M.B.; validation, N.G.D.-M., M.B.; formal analysis, N.G.D.-M., D.G.M.; investigation, D.G.M.; resources, D.G.M.; data curation, D.G.M.; writing — original draft preparation, N.G.D.-M.; writingreview and editing, D.G.M.; visualization, N.G.D.-M., D.G.M.; supervision, D.G.M.; project administration, A.V., D.G.M.; funding acquisition, A.V., D.G.M. All authors have read and agreed to the published version of the manuscript.

Funding: The work reported in this paper has been supported by grant PI10/1604 and PI18/01140 from the Fondo de Investigaciones Sanitarias of the Spanish Government, Fondo Europeo de Desarrollo Regional (FEDER) "Una manera de hacer Europa"/"A way of shaping Europe", and RTICC (Red Temática de Investigación Cooperativa en Cancer), and AGAUR grant number SGR771.

Institutional Review Board Statement: The study was conducted according to the guidelines of the Declaration of Helsinki, and approved by the Ethics Committee of the Hospital Universitari de Bellvitge (IDIBELL Ethics Committee, approval reference PR91/10, 6 May 2010). 
Informed Consent Statement: Informed consent was obtained from all subjects involved in the study. Acknowledgments: We thank CERCA Programme/Generalitat de Catalunya for institutional support.

Conflicts of Interest: The authors have no conflict of interest. The funders had no role in the design of the study; in the collection, analyses, or interpretation of data; in the writing of the manuscript, or in the decision to publish the results.

\section{References}

1. Bissell, M.J.; Hines, W.C. Why don't we get morecancer? A proposed role of the microenvironment in restraining cancer progression. Nat. Med. 2011, 17, 320. [CrossRef]

2. Hanahan, D.; Coussens, L.M. Accessories to the crime: Functions of cells recruited to the tumor microenvironment. Cancer Cell 2012, 21, 309. [CrossRef]

3. Hanahan, D.; Weinberg, R.A. Hallmarks of cancer: The next generation. Cell 2011, 144, 646. [CrossRef] [PubMed]

4. Kerbel, R.S. Tumor angiogenesis. N. Engl. J. Med. 2008, 358, 2039. [CrossRef] [PubMed]

5. Kalluri, R.; Zeisberg, M. Fibroblasts in cancer. Nat. Rev. Cancer 2006, 6, 392. [CrossRef] [PubMed]

6. Yamaguchi, H.; Sakai, R. Direct Interaction between Carcinoma Cells and Cancer Associated Fibroblasts for the Regulation of Cancer Invasion. Cancers 2015, 7, 2054. [CrossRef]

7. Li, J.; Chen, L.; Qin, Z. Multifaceted tumor stromal fibroblasts. Cancer Microenviron. 2012, 5, 187. [CrossRef]

8. Webber, J.; Steadman, R.; Mason, M.D.; Tabi, Z.; Clayton, A. Cancer exosomes trigger fibroblast to myofibroblast differentiation. Cancer Res. 2010, 70, 9621. [CrossRef]

9. Roulis, M.; Nikolaou, C.; Kotsaki, E.; Kaffe, E.; Karagianni, N.; Koliaraki, V.; Salpea, K.; Ragoussis, J.; Aidinis, V.; Martini, E.; et al. Intestinal myofibroblast-specific Tp12-Cox-2-PGE2 pathway links innate sensing to epithelial homeostasis. Proc. Natl. Acad. Sci. USA 2014, 111, E4658. [CrossRef]

10. Tjomsland, V.; Spångeus, A.; Välilä, J.; Sandström, P.; Borch, K.; Druid, H.; Falkmer, S.; Falkmer, U.; Messmer, D.; Larsson, M. Interleukin $1 \alpha$ sustains the expression of inflammatory factors in human pancreatic cancer microenvironment by targeting cancer-associated fibroblasts. Neoplasia 2011, 13, 664. [CrossRef] [PubMed]

11. Kogan-Sakin, I.; Cohen, M.; Paland, N.; Madar, S.; Solomon, H.; Molchadsky, A.; Brosh, R.; Buganim, Y.; Goldfinger, N.; Klocker, H.; et al. Prostate stromal cells produce CXCL-1, CXCL-2, CXCL-3 and IL-8 in response to epithelia-secreted IL-1. Carcinogenesis 2009, 30, 698. [CrossRef]

12. Dudás, J.; Fullár, A.; Bitsche, M.; Schartinger, V.; Kovalszky, I.; Sprinzl, G.M.; Riechelmann, H. Tumor-produced, active interleukin$1 \beta$ regulates gene expression in carcinoma-associated fibroblasts. Exp. Cell Res. 2011, 317, 2222. [CrossRef] [PubMed]

13. Berdiel-Acer, M.; Sanz-Pamplona, R.; Calon, A.; Cuadras, D.; Berenguer, A.; Sanjuan, X.; Paules, M.J.; Salazar, R.; Moreno, V.; Batlle, E.; et al. Differences between CAFs and their paired NCF from adjacent colonic mucosa reveal functional heterogeneity of CAFs, providing prognostic information. Mol. Oncol. 2014, 8, 1290. [CrossRef] [PubMed]

14. Bauer, M.; Su, G.; Casper, C.; He, R.; Rehrauer, W.; Friedl, A. Heterogeneity of gene expression in stromal fibroblasts of human breast carcinomas and normal breast. Oncogene 2010, 29, 1732. [CrossRef]

15. Wu, T.; Hong, Y.; Jia, L.; Wu, J.; Xia, J.; Wang, J.; Hu, Q.; Cheng, B. Modulation of IL-1 $\beta$ reprogrammes the tumor microenvironment to interrupt oral carcinogenesis. Sci. Rep. 2016, 6, 20208. [CrossRef]

16. Voronov, E.; Shouval, D.S.; Krelin, Y.; Cagnano, E.; Benharroch, D.; Iwakura, Y.; Dinarello, C.A.; Apte, R.N. IL-1 is required for tumor invasiveness and angiogenesis. Proc. Natl. Acad. Sci. USA 2003, 100, 2645. [CrossRef] [PubMed]

17. Xu, D.; Matsuo, Y.; Ma, J.; Koide, S.; Ochi, N.; Yasuda, A.; Funahashi, H.; Okada, Y.; Takeyama, H. Cancer cell-derived IL-1 $\alpha$ promotes HGF secretion by stromal cells and enhances metastatic potential in pancreatic cancer cells. J. Surg. Oncol. 2010, 102, 469. [CrossRef]

18. Mendoza-Rodríguez, M.; Arévalo Romero, H.; Fuentes-Pananá, E.M.; Ayala-Sumuano, J.T.; Meza, I. IL-1 $\beta$ induces up-regulation of BIRC3, a gene involved in chemoresistance to doxorubicin in breast cancer cells. Cancer Lett. 2017, 390, 39. [CrossRef]

19. Zhang, D.; Li, L.; Jiang, H.; Li, Q.; Wang-Gillam, A.; Yu, J.; Head, R.; Liu, J.; Ruzinova, M.B.; Lim, K.H.; et al. Tumor-Stroma IL1 $\beta$-IRAK4 Feedforward Circuitry Drives Tumor Fibrosis, Chemoresistance, and Poor Prognosis in Pancreatic Cancer. Cancer Res. 2018, 78, 1700 LP. [CrossRef]

20. Neuzillet, C.; Tijeras-Raballand, A.; Ragulan, C.; Cros, J.; Patil, Y.; Martinet, M.; Erkan, M.; Kleeff, J.; Wilson, J.; Apte, M.; et al. Inter- and intra-tumoral heterogeneity in cancer-associated fibroblasts of human pancreatic ductal adenocarcinoma. J. Pathol. 2019, 248, 51-65. [CrossRef]

21. Hsia, L.; Ashley, N.; Ouaret, D.; Wang, L.M.; Wilding, J.; Bodmer, W.F. Myofibroblasts are distinguished from activated skin fibroblasts by the expression of AOC3 and other associated markers. Proc. Natl. Acad. Sci. USA 2016, 113, E2162. [CrossRef]

22. Lewis, M.P.; Lygoe, K.A.; Nystrom, M.L.; Anderson, W.P.; Speight, P.M.; Marshall, J.F.; Thomas, G.J. Tumor-derived TGF-beta1 modulates myofibroblast differentiation and promotes HGF/SF-dependent invasion of squamous carcinoma cells. Br. Cancer J. 2004, 90, 822-832. [CrossRef]

23. Scotton, C.J.; Chambers, R.C. Molecular targets in pulmonary fibrosis: The myofibroblast in focus. Chest 2007, 132, 1311. [CrossRef]

24. Fuschiotti, P. Role of IL-13 in systemic sclerosis. Cytokine 2011, 56, 544. [CrossRef] [PubMed] 
25. Kendall, R.T.; Feghali-Bostwick, C.A. Fibroblasts in fibrosis: Novel roles and mediators. Front. Pharmacol. $2014,5,123$. [CrossRef] [PubMed]

26. Öhlund, D.; Elyada, E.; Tuveson, D. Fibroblast heterogeneity in the cancer wound. J. Exp. Med. 2014, 211, 1503. [CrossRef]

27. Costa, A.; Kieffer, Y.; Scholer-Dahirel, A.; Pelon, F.; Bourachot, B.; Cardon, M.; Sirven, P.; Magagna, I.; Fuhrmann, L.; Bernard, C.; et al. Heterogeneity and Immunosuppressive Environment in Human Breast Cancer. Cancer Cell 2018, 33, 463. [CrossRef]

28. Lauri, D.; Bertomeu, M.C.; Orr, F.W.; Bastida, E.; Sauder, D.; Buchanan, M.R. Interleukin-1 increases tumor cell adhesion to endothelial cells through an RGD dependent mechanism: In vitro and in vivo studies. Clin. Exp. Metastasis 1990, 8, 27. [CrossRef] [PubMed]

29. Giavazzi, R.; Garofalo, A.; Bani, M.R.; Abbate, M.; Ghezzi, P.; Boraschi, D.; Mantovani, A.; Dejana, E. Interleukin 1-induced augmentation of experimental metastases from a human melanoma in nude mice. Cancer Res. 1990, $50,4771$.

30. Erez, N.; Truitt, M.; Olson, P.; Hanahan, D. Cancer-Associated Fibroblasts Are Activated in Incipient Neoplasia to Orchestrate Tumor-Promoting Inflammation in an NF-kappaB-Dependent Manner. Cancer Cell 2010, 17, 125. [CrossRef] [PubMed]

31. Arlt, A.; Vorndamm, J.; Müerköster, S.; Yu, H.; Schmidt, W.E.; Fölsch, U.R.; Schäfer, H. Autocrine production of interleukin 1beta confers constitutive nuclear factor kappaB activity and chemoresistance in pancreatic carcinoma cell lines. Cancer Res. 2002, 62, 910. [PubMed]

32. Young, H.; Rowling, E.J.; Bugatti, M.; Giurisato, E.; Luheshi, N.; Arozarena, I.; Acosta, J.C.; Kamarashev, J.; Frederick, D.; Cooper, T.; et al. An adaptative signaling network in melanoma inflammatory niches confers tolerance to MAPK signaling inhibition. J. Exp. Med. 2017, 214, 1691-1710. [CrossRef] [PubMed]

33. Su, S.; Chen, J.; Yao, H.; Liu, J.; Yu, S.; Lao, L.; Wang, M.; Luo, M.; Xing, Y.; Chen, F.; et al. CD10 GPR77 ${ }^{+}$Cancer-Associated Fibroblasts Promote Cancer Formation and Chemoresistance by Sustaining Cancer Stemness. Cell 2018, 172, 841. [CrossRef] [PubMed]

34. Öhlund, D.; Handly-Santana, A.; Biffi, G.; Elyada, E.; Almeida, A.S.; Ponz-Sarvise, M.; Corbo, V.; Oni, T.E.; Hearn, S.A.; Lee, E.J.; et al. Distinct populations of inflammatory fibroblasts and myofibroblasts in pancreatic cancer. J. Exp. Med. 2017, $214,579$. [CrossRef] [PubMed]

35. Gonçalves-Ribeiro, S.; Díaz-Maroto, N.G.; Berdiel-Acer, M.; Soriano, A.; Guardiola, J.; Martínez-Villacampa, M.; Salazar, R.; Capellà, G.; Villanueva, A.; Martínez-Balibrea, E. Carcinoma-associated fibroblasts affect sensitivity to oxaliplatin and 5FU in colorectal cancer cells. Oncotarget 2016, 7, 59766. [CrossRef]

36. Rider, P.; Carmi, Y.; Cohen, I. Biologics for Targeting Inflammatory Cytokines, Clinical Uses, and Limitations. Int. Cell J. Biol. 2016, 2016, 9259646. [CrossRef]

37. Grassi, A.; Perilli, L.; Albertoni, L.; Tessarollo, S.; Mescoli, C.; Urso, E.D.L.; Fassan, M.; Rugge, M.; Zanovello, P. A coordinate deregulation of microRNAs expressed in mucosa adjacent to tumor predicts relapse after resection in localized colon cancer. Mol. Cancer 2018, 17, 17. [CrossRef]

38. Sanz-Pamplona, R.; Berenguer, A.; Cordero, D.; Molleví, D.G.; Crous-Bou, M.; Sole, X.; Paré-Brunet, L.; Guino, E.; Salazar, R.; de Santos, C.; et al. Aberrant gene expression in mucosa adjacent to tumor reveals a molecular crosstalk in colon cancer. Mol. Cancer 2014, 13, 46. [CrossRef]

39. Elyada, E.; Bolisetty, M.; Laise, P.; Flynn, W.; Courtois, E.; Burkhart, R.; Teinor, J.; Belleau, P.; Biffi, G.; Lucito, M.; et al. Crossspecies single-cell analysis of pancreatic ductal adenocarcinoma reveals antigen-presenting cancer-associated fibroblasts. Cancer Discov. 2019, 9, 1102-1123. [CrossRef]

40. Dominguez, C.; Müller, S.; Keerthivasan, S.; Koeppen, H.; Hung, J.; Gierke, S.; Breart, B.; Foreman, O.; Bainbridge, T.; Castiglioni, A.; et al. Single-cell RNA sequencing reveals stromal evolution into LRRC15+ myofibroblasts as a determinant of patient response to cancer immunotherapy. Cancer Discov. 2020, 10, 232-253. [CrossRef] [PubMed]

41. Guillen, N.; Sanz-Pamplona, R.; Berdiel-Hacer, M.; Cimas, F.J.; García, E.; Gonçalves-Ribeiro, S.; Albert, N.; García-Vicién, G.; Capella, G.; Moreno, V.; et al. Noncanonical TGF $\beta$ pathway relieves the blockade of IL1 $\beta$ /TGF $\beta$-mediated crosstalk between tumor and stroma: TGFBR1 and TAK1 inhibition in colorectal cancer. Clin. Cancer. Res. 2019, 25, 4466-4479. [CrossRef] [PubMed]

42. Biffi, G.; TOni, E.; Spielman, B.; Hao, Y.; Elyada, E.; Park, Y.; Preall, J.; Tuveson, D.A. Il1-induced JAK/STAT signaling is antagonized by TGFb to shape CAF heterogeneity in pancreatic ductal adenocarcinoma. Cancer Discov. 2019, 9, 282-301. [CrossRef]

43. Hurwitz, H.; Van Cutsem, E.; Bendell, J.; Hidalgo, M.; Li, C.; Garrido Salvo, M.; Macarulla, T.; Sahai, V.; Sama, A.; Greeno, E.; et al. Ruxolitinib+ capecitabine in advanced/metastatic pancreatic cancer after disease progression/intolerance to first-line therapy: JANUS 1 and 2 randomized phase III studies. Investig. New Drugs 2018, 36, 683-695. [CrossRef] [PubMed]

44. Hurwitz, H.I.; Uppal, N.; Wagner, S.A.; Bendell, J.C.; Beck, J.T.; Wade III, S.M.; Nemunaitis, J.J.; Stella, P.J.; Pipas, J.M.; Wainberg, Z.A.; et al. Ranzomized, double-blind, phase II study of Ruxolitinib or placebo in combination with Capecitabine in patients with metastatic pancreatic cancer from whom therapy with Gemcitabine has failed. Clin. J. Oncol. 2015, 33, 4039. [CrossRef] [PubMed] 